\title{
Short stature of mothers from an area endemic for undernutrition is associated with obesity, hypertension and stunted children: a population-based study in the semi-arid region of Alagoas, Northeast Brazil
}

\author{
Haroldo S. Ferreira*, Fabiana A. Moura, Cyro R. Cabral Júnior, Telma M. M. T. Florêncio, \\ Regina C. Vieira and Monica L. de Assunção \\ Faculdade de Nutrição, Universidade Federal de Alagoas, Campus A. C. Simões, Campus Universitário, 57072-970 Maceió, \\ AL, Brazil \\ (Received 17 January 2008 - Revised 22 July 2008 - Accepted 31 July 2008 - First published online 18 November 2008)
}

The objectives of the study were to investigate whether the health conditions of mothers with short stature differed from those with normal stature, and to establish if these aspects were associated with the health of the offspring. Data relating to health and socio-economic, demographic and anthropometric conditions were collected from a probabilistic sample population consisting of 1180 mothers and 1511 children $(<10$ years) living in the semi-arid region of the State of Alagoas, Brazil. Mothers were categorised according to stature, with those in the 1st quartile being defined as of short stature and those in the 4th quartile being defined as of normal stature and serving as a reference for the comparison of variables of interest. Following verification that maternal stature fulfilled parametric assumptions, its associations with the other variables were determined by calculating Pearson correlation coefficients. After excluding strongly self-correlated variables $(r \geq 0 \cdot 70)$, the remaining variables were analysed by multiple linear regression. The results showed that low maternal stature was independently associated with obesity (percentage body fat $\geq 30 ; P=0.045$ ), abdominal adiposity (waist:hip ratio $\geq 0.85 ; P=0.007$ ) and high systolic blood pressure ( $\geq 140 \mathrm{mmHg}$; $P=0.006)$. Short maternal stature was associated with low birth weight $(<3000 \mathrm{~g} ; P=0.01)$ and stunting (height-for-age $Z$ score $<-2$; $P=0.019)$ in the offspring. Thus, in the semi-arid region of Alagoas, women of short stature presented a higher prevalence of chronic degenerative diseases and produced less healthy children than women of normal stature.

Anthropometry: Nutritional status: Stunting: Programming

In line with the majority of developing countries, Brazil is experiencing a process of epidemiological transition characterised by a reduction in the prevalence of infectious-parasitic diseases together with an increase in morbidity and mortality caused by chronic non-transmissible diseases ${ }^{(1)}$. At the same time, the population is undergoing a nutritional transition in which undernutrition is replaced by obesity, a condition which is rapidly becoming a serious public health problem $^{(2)}$. National surveys conducted by the Instituto Brasileiro de Geografia e Estatística (Brazilian Institute of Geography and Statistics) ${ }^{(3)}$ have revealed that the prevalence of weight deficit in Brazilian women decreased from 10.2\% in 1974-5 to $5.4 \%$ in $2002-3$. In contrast, the frequency of excess body weight increased from $28.6 \%$ to $39.2 \%$, respectively, over the same time period.

One explanation for this phenomenon relates to the modernisation and urbanisation of society, which is associated with alterations in food consumption habits and particularly with a tendency towards high-energy foods (simple carbohydrates and fats) ${ }^{(4)}$. However, following a study of the dietary profile of a poor population living in a shanty town in Maceió (capital of the State of Alagoas, Brazil),
Florencio et al. ${ }^{(5)}$ discovered that, although the women ingested an average of $7238 \mathrm{~kJ}(1730 \mathrm{kcal})$ daily (i.e. about $66 \%$ of the recommended intake), the prevalence of overweight/obesity within the group was in the order of $32 \%$. It is clear, therefore, that the high prevalence of overweight/ obesity among such a population cannot be explained exclusively on the basis of greater energy intake. Within this context, the thrifty phenotype, also known as Barker's hypothesis ${ }^{(6,7)}$, may be applicable. According to this idea, when nutritional deprivation occurs at an early age, especially in the prenatal stage and/or during the first 3 years of life, the individual undergoes metabolic adaptations that could result in greater susceptibility to obesity in adult life ${ }^{(8)}$.

It is recognised that low birth weight caused by intra-uterine undernutrition $^{(9)}$, along with short stature at an adult age occasioned by poor health conditions during infancy ${ }^{(10)}$, are risk factors for chronic non-transmissible diseases chiefly in women ${ }^{(11)}$. Since growth is particularly intense during the first 2 years of life, nutritional problems during this period may result in diverse manifestations, depending on the nature of the process. Acute situations produce loss of weight and result in emaciated children, whereas chronic 
undernutrition results in reduced linear growth and, depending on the magnitude of the deficit, stunting. Thus chronic undernutrition hinders the growth potential of children and result in adults of low stature ${ }^{(12)}$.

Although obesity in children is increasing and is becoming an important epidemiological problem, infantile undernutrition, which is mainly associated with poverty and low maternal stature ${ }^{(13)}$, is still of serious concern in many parts of Brazil ${ }^{(14)}$. The State of Alagoas in the north-eastern region of Brazil is one of the poorest of the whole federation, and is characterised by the lowest social indicators, the greatest prevalence of infantile undernutrition, precarious basic sanitation, and an elevated rate of illiteracy and high heightfor-age deficit ${ }^{(15)}$. Within this context, the population of the semi-arid zone is particularly exposed to the risks of food insecurity and nutritional deficiencies by virtue of geographically and historically unfavourable socio-economic factors ${ }^{(16)}$.

In consideration of the above, the objectives of the present study were to determine if the health conditions of mothers with short stature differed from those of mothers with normal stature, and to establish if these aspects were associated with the the health of their offspring.

\section{Subjects and methods}

The described investigation formed part of a project entitled 'Nutrition and health among the infant-maternal population of the semi-arid region of Alagoas'. Details of the study were presented to, and approved by, the Ethical Committee of the Universidade Federal de Alagoas (Maceió-AL, Brazil). All experiments were conducted according to the guidelines established by the Conselho Nacional de Ética em Pesquisa (Ministério da Saúde, Brasília, DF, Brazil). The purpose and scope of the study were explained carefully to the selected mothers, and those who agreed to participate (together with their respective offspring) signed an appropriate form of consent before the commencement of the study.

\section{Study population}

The study population comprised of children younger than 10 years of age and their respective mothers living in the semiarid zone of Alagoas. Assuming the prevalence of heightfor-age deficit to be $9.5 \%$ (estimated during a previous study in the same area ${ }^{(17)}$, a sampling error of $\pm 1.5 \%$ and a CI of $95 \%$, the estimated number of children required for the study was determined to be 1467 plus $10 \%$ extra to allow for possible drop-outs. The number of mothers required to participate in the project was lower, of course, since many mothers had more than one child.

In order to attain the required number of children, a multistage sampling design was adopted, and this consisted of three steps. First, fourteen of the thirty-seven municipalities of the semi-arid region were randomly selected on the basis of proportional size probability sampling; second, four sectors within each municipality were established; finally, a single starting location was defined within each sector from which to commence recruitment by visitation of twenty-four consecutive domiciles in which children aged $0-10$ years were living. This systematic approach permitted 1344 randomly selected residences to be visited and an equal number of mothers, together with all of their eligible children, were evaluated. The criteria for exclusion from the study were: mothers who were pregnant, mothers younger than 18 years old and children presenting anatomical deformities, prostheses or any condition that could hinder the comparison of their measurements with the anthropometric reference data.

\section{Collection of data}

Data were collected between January and March 2007. Each mother was interviewed by the research team and answered a structured, and previously tested, questionnaire concerning health (age at menarche, number of children, history of child loss) and socio-economic (family income, schooling of the mother and of the head of the family, presence of a toilet in the domicile), demographic (location of domicile, total number of family members) and lifestyle (smoking and drinking habits) variables.

Anthropometric measurements of the mothers were performed with the subjects barefoot and using light clothes, and included body weight, height, waist circumference, hip circumference and body fat percentage. Body weight was determined using a Marte ${ }^{\circledR}$ (model PP180; São Paulo, Brazil) electronic scale with a maximum tare of $150 \mathrm{~kg}$ and a precision of $100 \mathrm{~g}$. At the start of each research day, the scale was calibrated against a standard weight. Height was determined with the individual in an orthostatic position with the aid of a portable stadiometer consisting of a nonextendable $2 \mathrm{~m}$ measuring tape graduated in $0.1 \mathrm{~cm}$ divisions. Waist circumference was measured either at the level of the anatomical waist or, when this was not obvious, at a level midway between the iliac crest and the lower anterior superior rib $^{(18)}$. Hip circumference was measured at the maximum perimeter between waist and thigh. Both waist circumference and hip circumference were determined using a non-extendable tape graduated in $0 \cdot 1 \mathrm{~cm}$ divisions. BMI was given by the quotient of body weight $(\mathrm{kg})$ and the square of the height $\left(\mathrm{m}^{2}\right)$.

Anthropometric data of the children included body weight, height and birth weight. The body weights of children under 2 years old were determined by weighing the child in the arms of the pre-weighed mother. The length of the child was measured using a horizontal paediatric stadiometer with a non-extendable measuring tape graduated in $0.1 \mathrm{~cm}$ divisions. Blood pressure was determined using an Omron ${ }^{\circledR}$ digital instrument (model HEM-705 CP; Omron Corp., Tokyo, Japan) that was calibrated weekly with the aid of a column sphygmomanometer maintained especially for this purpose. Two values of blood pressure were obtained with the mothers sitting down. The first measurement was performed $15 \mathrm{~min}$ after commencing the interview and the second was performed after a minimum interval of $10 \mathrm{~min}$. Whenever there was a discrepancy greater than $5 \mathrm{mmHg}$ between the two values, a third measurement was performed and a mean value calculated by disregarding the value showing the largest deviation. Subjects were stratified according to blood pressure following the recommendations of the IV Brazilian Arterial Hypertension Guidelines as follows ${ }^{(19)}$ : normal systolic blood pressure $(\mathrm{SBP}) \leq 139 \mathrm{mmHg}$; high $\mathrm{SBP} \geq 140 \mathrm{mmHg}$; normal diastolic blood pressure $\leq 89 \mathrm{mmHg}$; high diastolic blood pressure $\geq 90 \mathrm{mmHg}$. 
Mothers were classified according to their nutritional status as recommended by the WHO as follows ${ }^{(20)}$ : thinness (BMI $<18.5 \mathrm{~kg} / \mathrm{m}^{2}$ ); normal (BMI between 18.5 and $24.9 \mathrm{~kg} / \mathrm{m}^{2}$ ); overweight (BMI between 25 and $29.9 \mathrm{~kg} / \mathrm{m}^{2}$ ); obese $\left(\mathrm{BMI}>30 \cdot 0 \mathrm{~kg} / \mathrm{m}^{2}\right)$. Abdominal obesity was defined as a waist:hip ratio $\geq 0 \cdot 85^{(20,21)}$. The percentage of body fat was estimated by bioelectric impedance using an Omron digital, bipolar device (model HBF300; Omron Corp.). Mothers presenting a percentage of body fat $\geq 30 \%$ were classified as obese. Mothers were also classified according to stature quartile. Those assigned to the 1 st quartile $(\leq 1.52 \mathrm{~m})$ were considered to be of short stature and had the greatest probability of having suffered malnutrition during one or more phases of growth and development ${ }^{(11)}$; mothers from the 4th quartile $(\geq 1.59 \mathrm{~m})$ were taken to be of normal stature and served as a reference for comparison of the variables of interest.

Family income was based on per capita earnings (either $\leq$ or $>$ US\$ 1.00/d), and also according to a modified version of the Brazilian economic classification criteria as proposed by the Associação Brasileira de Empresas de Pesquisa ${ }^{(22)}$, which is based on the scores achieved by the family as a function of level of schooling of the head of the household and by the possession of certain basic items. Five economic classes were identified using this system, namely, A (25-34 points), B (1724 points), $\mathrm{C}(11-16$ points), $\mathrm{D}(6-10$ points $)$ and $\mathrm{E}(0-5$ points $)$.

Children were classified according to nutritional status on the basis of weight-for-height and height-for-age $Z$ scores as proposed by the $\mathrm{WHO}^{(20)}$. Wasting was defined by a weight-for-height $Z$ score $<-2$, whilst obesity was characterised by a weight-for-height $Z$ score $>2$. Short stature (stunting) was defined by a height-for-age $Z$ score $<-2$.

\section{Statistical analysis}

The data were entered into the program Epi Info 3.2.2 in duplicate (two independent processes in order to eliminate errors of transcription) and analysed with the aid of the SPSS 14.0 software (SPSS Inc., Chicago, IL, USA). In the bivariate analysis, the frequencies of variables observed in mothers classified in the 1 st and 4 th stature quartiles were compared by means of the $\chi^{2}$ test. OR and $95 \%$ CI were used to evaluate the association between such variables. Multiple linear regression analysis was carried out following tests for multivariate normality and homogeneity of the variances of the errors. Variables that were strongly self-correlated according to the Pearson correlation coefficient $(r \geq 0 \cdot 70)$ were excluded in order to eliminate the problems of multi-collinearity ${ }^{(23)}$. Maternal stature (1st and 4th quartiles) was employed as the independent variable in the model, and all variables that were not significantly associated $(P \geq 0 \cdot 1)$ with low stature were removed from the final model by a process of backward elimination.

\section{Results}

Of the 1344 domiciles that were visited by the research team, twenty-six $(1.9 \%)$ were excluded from the study since data could not be collected either because the mother was absent from the house at the time of the visit or the mother refused to participate in the investigation. A total of 1317 mothers were subsequently interviewed and, following the exclusion of 150 pregnant women and fourteen teenage mothers $(<18$ years old), 1180 mothers and 1511 children formed the sample population.

The general characteristics of the study population of mothers are presented in Table 1 . The majority (58\%) of mothers lived in rural areas, $40 \%$ had less than 4 years of schooling, and $28.1 \%$ had outside jobs as well as taking care of the house and family. In respect of their economic situation, $62.6 \%$ had a per capita family income below US\$1.00/d, and $86.4 \%$ were classified as economic class D or E. Only $13.6 \%$ of the mothers were classified as class $\mathrm{B}$ or $\mathrm{C}$, and none were

Table 1. General characteristics of mothers living in the semi-arid region of the State of Alagoas, Brazil

(Numbers and percentages or mean values, standard deviations and ranges)

\begin{tabular}{|c|c|c|c|c|c|}
\hline Variable & $n$ & $\%$ & Mean & SD & Range \\
\hline Age (years) & & - & $30 \cdot 2$ & $7 \cdot 7$ & $18-53$ \\
\hline Number of family members & & - & 5.05 & 1.94 & $2-16$ \\
\hline \multicolumn{6}{|l|}{ Per capita family income } \\
\hline$<$ US\$1.00/d & 706 & $62 \cdot 6$ & & - & \\
\hline \multicolumn{6}{|l|}{ Source of water } \\
\hline Well, reservoir or river & 493 & $41 \cdot 8$ & & - & \\
\hline Presence of toilet in the house & 369 & $31 \cdot 3$ & & - & \\
\hline Height $(m)$ & & - & 1.56 & 0.07 & $1 \cdot 34-1 \cdot 84$ \\
\hline BMI $\left(\mathrm{kg} / \mathrm{m}^{2}\right)$ & & - & $25 \cdot 4$ & $5 \cdot 3$ & $15 \cdot 4-45 \cdot 3$ \\
\hline$<18.5$ & 46 & $3 \cdot 9$ & & - & \\
\hline $18 \cdot 5-24.9$ & 594 & $50 \cdot 9$ & & - & \\
\hline $25 \cdot 0-29 \cdot 9$ & 339 & $29 \cdot 0$ & & - & \\
\hline$\geq 30$ & 189 & $16 \cdot 2$ & & - & \\
\hline Waist:hip ratio & & - & 0.82 & 0.07 & $0.60-1.07$ \\
\hline$\geq 0.85$ & 355 & $30 \cdot 6$ & & - & \\
\hline Percentage of body fat & & - & $27 \cdot 4$ & $7 \cdot 43$ & $7 \cdot 3-49 \cdot 9$ \\
\hline$<30$ & 717 & 61.5 & & - & \\
\hline$\geq 30$ & 448 & 38.5 & & - & \\
\hline Systolic blood pressure (mmHg) & & - & $120 \cdot 9$ & $16 \cdot 3$ & $84-208$ \\
\hline$\leq 120 \mathrm{mmHg}$ & 648 & 54.9 & & - & \\
\hline $121-139 \mathrm{mmHg}$ & 398 & $33 \cdot 7$ & & - & \\
\hline$\geq 140 \mathrm{mmHg}$ & 131 & $11 \cdot 1$ & & - & \\
\hline
\end{tabular}


classified as class A. When the mothers were stratified according to BMI, $42.5 \%$ were determined to be overweight and $16.2 \%$ were obese. On the basis of percentage body fat, the number of obese mothers increased to $38.5 \%$. With respect to blood pressure, $11.1 \%$ of the mothers exhibited high SBP. In most domiciles $(75.3 \%)$ men acted as the head of household; of these, $47 \%$ were self-employed and $14 \%$ worked in either government or private companies. The rate of unemployment amongst men was approximately $11 \%$.

Table 2 shows mothers of short and normal stature distributed according to socio-economic and demographic variables. Following bivariate analysis, it was possible to observe that mothers of short stature differed significantly $(P<0.05)$ from those of normal stature in the following aspects: (i) most lived in rural areas; (ii) they had lower per capita family income; (iii) they were classified in economic classes D and E; (iv) they had larger families; (v) they had received a lower level of schooling (and this included also the head of the household); (vi) they lived in domiciles lacking toilet facilities; (vi) their domiciles had no access to the public water supply.

Table 3 shows the distribution of mothers of short and normal stature according to anthropometric, lifestyle and health variables. Bivariate analysis demonstrated that the frequency of abdominal obesity was significantly larger within the short-stature group compared with mothers of normal stature (61.5 v. $38.5 \%$; OR 2.13; $95 \%$ CI $1.48,3.07 ; P<0.001)$. There was no significant difference $(P=0 \cdot 14)$ between the two groups with respect to obesity as determined by BMI. However, there was a statistically significant tendency towards obesity when percentage of body fat was considered (53.6 v. $46.4 \%$; OR 1.33 ; $95 \%$ CI $0.95,1.86 ; P=0.09)$.
A greater prevalence of high SBP was observed amongst mothers of short stature $(P=0.0001)$, such that the risk of high SBP was 3-fold higher in the short-stature group compared with the normal-stature group.

As shown in Table 4, the prevalence of undernutrition amongst children born from mothers of short stature was significantly greater compared with children born from mothers of normal stature, independent of the indicator considered.

According to multivariate analysis, the variables that remained significantly associated $(P<0 \cdot 1)$ with mothers of short stature are indicated in the last columns of Tables 2, 3 and 4 . Thus, short stature was associated with higher average age, a lower level of schooling ( $\leq 4$ years), inadequate drinking water (well, reservoir or river), the occurrence of menarche earlier in life, a higher frequency of high percentage body fat, an increased waist:hip ratio and a higher SBP. Moreover, short stature in mothers was associated with children born with low weight $(<3000 \mathrm{~g})$ and with stunted children (height-for-age $Z$ score $<-2)$. Diastolic blood pressure, total family income and BMI were not included in the multiple linear regression model since they correlated strongly $(r>0.7)$ with SBP, per capita income and percentage of body fat, respectively, which were already considered in the analysis.

\section{Discussion}

In the present study, it was assumed that short stature in women was an indicator of the occurrence of undernutrition during one or more phases of growth, a condition that is acknowledged to be a consequence of poor socio-economic factors ${ }^{(6)}$. However, multivariate analysis revealed that maternal short

Table 2. Distribution of mothers of short and normal stature living in the semi-arid region of the State of Alagoas according to socioeconomic, demographic and health variables

(Numbers and percentages with odds ratios and $95 \%$ confidence intervals)

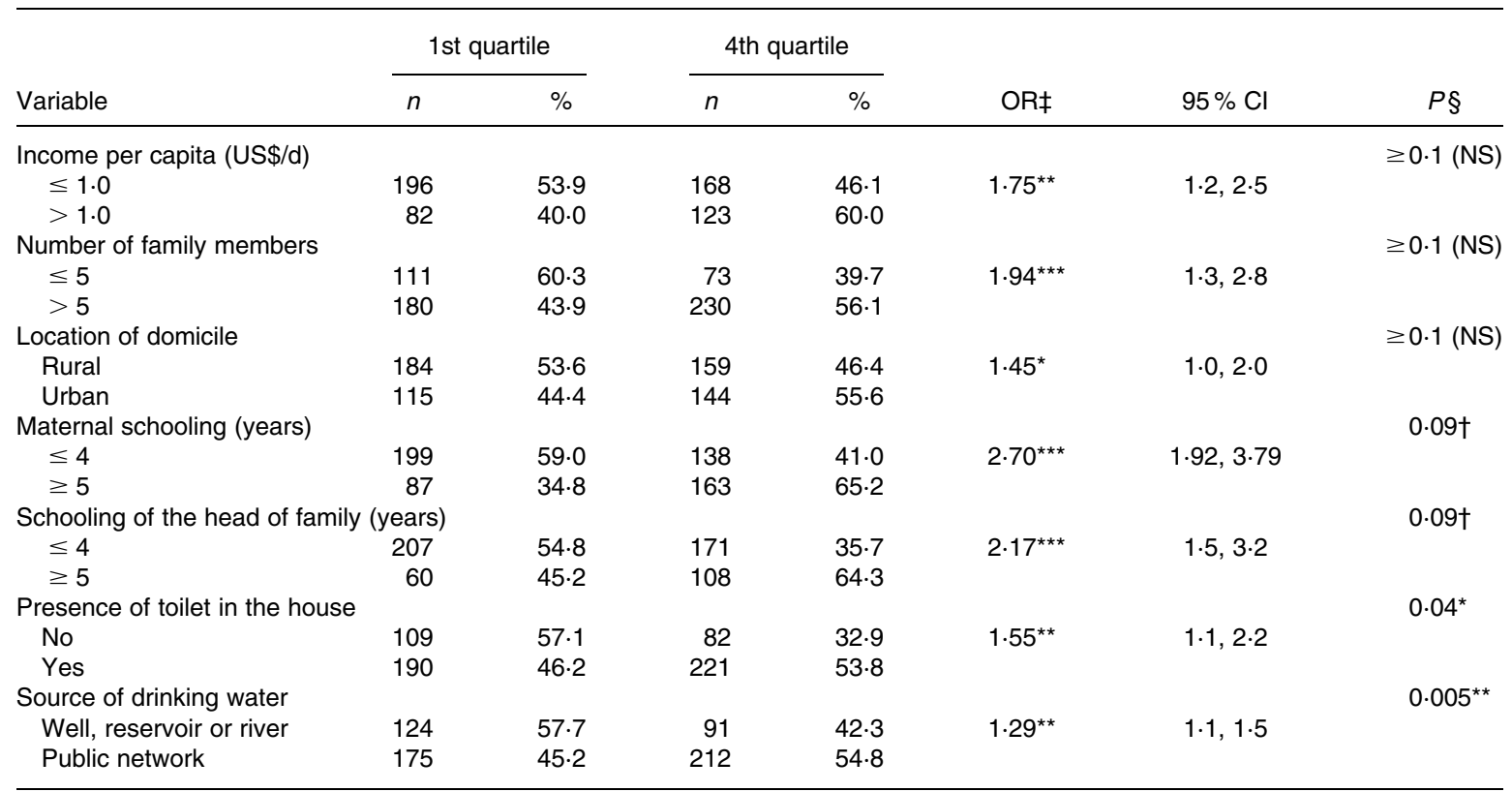

${ }^{\star} P<0.05,{ }^{* *} P<0.01,{ }^{\star * \star} P<0.001$

$+P<0 \cdot 1$.

$\ddagger$ Statistical significance tested using bivariate analyses $\left(\chi^{2}\right.$ test $)$

$\S$ Statistical significance tested using multivariate analyses (multiple linear regression). 
Table 3. Distribution of mothers of short and normal stature living in the semi-arid region of the State of Alagoas according to demographic, anthropometric and health variables

(Numbers and percentages with odds ratios and $95 \%$ confidence intervals)

\begin{tabular}{|c|c|c|c|c|c|c|c|}
\hline \multirow[b]{2}{*}{ Variable } & \multicolumn{2}{|c|}{ 1st quartile } & \multicolumn{2}{|c|}{ 4th quartile } & \multirow[b]{2}{*}{ OR $\ddagger$} & \multirow[b]{2}{*}{$95 \% \mathrm{Cl}$} & \multirow[b]{2}{*}{$P \S$} \\
\hline & $n$ & $\%$ & $n$ & $\%$ & & & \\
\hline \multicolumn{5}{|l|}{ Age (years) } & \multicolumn{2}{|c|}{$P<0.001^{\star \star *}$} & $0.002^{\star *}$ \\
\hline Mean & \multirow{2}{*}{\multicolumn{2}{|c|}{$\begin{array}{r}31.5 \\
7.9\end{array}$}} & \multicolumn{2}{|c|}{$28 \cdot 5$} & & & \\
\hline SD & & & \multicolumn{2}{|c|}{6.7} & \multirow{2}{*}{\multicolumn{2}{|c|}{$P=0.188(\mathrm{NS})$}} & \\
\hline Age at menarche (years) & & & & & & & $0.026^{\star}$ \\
\hline Mean & \multicolumn{2}{|c|}{$13 \cdot 0$} & \multicolumn{2}{|c|}{$13 \cdot 2$} & & & \\
\hline SD & \multicolumn{2}{|c|}{1.7} & \multicolumn{2}{|c|}{1.6} & & & \\
\hline BMI $\left(\mathrm{kg} / \mathrm{m}^{2}\right)$ & & & & & & & $\|$ \\
\hline$\geq 30$ & 52 & $56 \cdot 5$ & 40 & $43 \cdot 5$ & 1.43 (NS) & $0 \cdot 91,2 \cdot 24$ & \\
\hline$<30$ & 237 & $47 \cdot 6$ & 261 & $52 \cdot 4$ & & & \\
\hline Percentage body fat & & & & & & & $0.043^{\star}$ \\
\hline$\geq 30$ & 120 & $53 \cdot 6$ & 104 & $46 \cdot 4$ & $1.33 \dagger$ & $0.95,1.86$ & \\
\hline$<30$ & 169 & 46.4 & 195 & 53.6 & & & \\
\hline Waist:hip ratio & & & & & & & $0.007^{* *}$ \\
\hline$\geq 0.85$ & 112 & 61.5 & 70 & $38 \cdot 5$ & $2 \cdot 13^{\star \star \star}$ & $1.48,3.07$ & \\
\hline$<0.85$ & 171 & $42 \cdot 8$ & 228 & $57 \cdot 2$ & & & \\
\hline Systolic blood pressure $(\mathrm{mmHg})$ & & & & & & & $0.006^{* *}$ \\
\hline$\geq 140$ & 47 & $72 \cdot 3$ & 18 & $27 \cdot 7$ & $3.07^{* *}$ & $1 \cdot 74,5 \cdot 44$ & \\
\hline$<140$ & 242 & 45.9 & 285 & $34 \cdot 1$ & & & \\
\hline Loss of child by mortality & & & & & & & $\geq 0.1$ (NS) \\
\hline Yes & 129 & $55 \cdot 6$ & 103 & $44 \cdot 4$ & $1.47^{*}$ & $1 \cdot 0,2 \cdot 0$ & \\
\hline No & 170 & $45 \cdot 9$ & 200 & $54 \cdot 1$ & & & \\
\hline Smoking habits & & & & & & & $0.008^{\star \star}$ \\
\hline Yes & 20 & $66 \cdot 7$ & 10 & 33.3 & $2 \cdot 16^{\star}$ & $0.9,5.0$ & \\
\hline No & 271 & $48 \cdot 0$ & 293 & $62 \cdot 0$ & & & \\
\hline
\end{tabular}

${ }^{*} P<0.05,{ }^{* *} P<0.01,{ }^{* * *} P<0.001$.

† Statistically significant tendency towards obesity, according to bivariate analysis $(P<0.1$ and $\geq 0.05)$.

$\ddagger$ Statistical significance tested using bivariate analyses ( $\chi^{2}$ test) except for the variables age and age at menarche, which were tested using Student's $t$ test.

$\S$ Statistical significance tested using multivariate analyses (multiple linear regression).

\| This variable was strongly correlated $(r>0.7)$ with the percentage of body fat and hence was removed from multivariate analysis.

stature was not associated with low per capita income or with low economic class. In contrast, other socio-economic variables were independently associated with maternal short stature including low level of schooling, lack of a toilet in the home and sources of drinking water other than the public supply. According to Watkins ${ }^{(24)}$, these variables are indicators of the quality of public health and of the economic development of a population. In particular, families deprived of access to the public water network are the poorest of all and are included in class $E^{(25)}$. The results of the present study showed that the majority of women studied were from classes D and E, demonstrating that the low social economic status of the sample population was somewhat homogeneous, a factor that probably explains the lack of association between short stature and income or class.

Assuming that undernutrition in early life predisposes obesity in adulthood, a hypothesis supported by Ferreira et al. ${ }^{(11)}$, the situation of populations that are submitted to chronic hunger

Table 4. Distribution of children living in the semi-arid region of the State of Alagoas according to the stature quartiles of their mothers, considering anthropometric and health variables

(Numbers and percentages with odds ratios and $95 \%$ confidence intervals)

\begin{tabular}{|c|c|c|c|c|c|c|c|}
\hline \multirow[b]{2}{*}{ Variable } & \multicolumn{2}{|c|}{ 1st quartile } & \multicolumn{2}{|c|}{ 4th quartile } & \multirow[b]{2}{*}{ OR† } & \multirow[b]{2}{*}{$95 \% \mathrm{Cl}$} & \multirow[b]{2}{*}{$P \ddagger$} \\
\hline & $n$ & $\%$ & $n$ & $\%$ & & & \\
\hline \multicolumn{5}{|c|}{ Weight at birth (g) } & \multirow{3}{*}{1.69} & & \multirow[t]{3}{*}{$0.002^{\star *}$} \\
\hline$<3000$ & 108 & $61 \cdot 0$ & 69 & $39 \cdot 0$ & & $1 \cdot 2,2 \cdot 4$ & \\
\hline$\geq 3000$ & 276 & $48 \cdot 1$ & 298 & $51 \cdot 9$ & & & \\
\hline \multicolumn{3}{|c|}{ Weight-for-height $Z$ score } & & & \multirow{3}{*}{$2 \cdot 67^{\star}$} & & \multirow[t]{3}{*}{$\geq 0.1$ (NS) } \\
\hline$<-2$ & 19 & 73.1 & 7 & $26 \cdot 9$ & & $1 \cdot 1,6 \cdot 4$ & \\
\hline$\geq-2$ & 365 & $50 \cdot 3$ & 360 & $49 \cdot 7$ & & & \\
\hline \multicolumn{3}{|c|}{ Height-for-age $Z$ score } & & & \multirow{3}{*}{$3 \cdot 94^{\star \star \star}$} & & \multirow[t]{3}{*}{$0.019^{*}$} \\
\hline$<-2$ & 52 & $78 \cdot 8$ & 14 & $21 \cdot 2$ & & $2 \cdot 1,7 \cdot 3$ & \\
\hline$\geq-2$ & 332 & 48.5 & 353 & 51.5 & & & \\
\hline
\end{tabular}

${ }^{*} P<0.05,{ }^{* *} P<0.01,{ }^{* * *} P<0.001$.

† Statistical significance tested using bivariate analyses $\left(\chi^{2}\right.$ test)

$\ddagger$ Statistical significance tested using multivariate analyses (multiple linear regression). 
is particularly deleterious because they not only suffer the consequences of undernutrition during infancy but are also more susceptible to obesity and the risk of CVD in later life. In the present study, the frequency of obesity and elevated waist:hip ratio and SBP, three key variables that define the metabolic syndrome, were higher amongst women included in the 1st stature quartile compared with those of the 4th quartile. Similar results were reported in a previous study conducted by Florêncio et al. ${ }^{(10)}$ in a shanty town of Maceió. In an early study conducted by the same workers in another shanty town in Maceió(11), the risk of hypertension in women of short stature was shown to be 3.08-fold greater compared with women of normal stature. It has been suggested that inefficient endocrine control, caused by reduced levels of insulin-like growth factor-1 and/or altered expression of the hormone receptors that result from nutritional deprivation during early life, may exert a negative influence on the general development of the individual and of the vascular system in particular, thus leading to an increased risk of hypertension ${ }^{(26)}$.

The present study has shown that women in the 1st stature quartile produced children with low weight at birth and with low height-for-age $Z$ scores, a finding that is not surprising since such mothers were poorer than those of the 4th quartile reference. The association between these variables persisted in all statistical tests, however, suggesting that the metabolic and physiological adaptations resulting from nutritional deprivation at an early age may be passed on to future generations. According to Emanuel ${ }^{(27)}$, stature and pre-gestational weight are strong and independent predictors of offspring with low weight at birth. Further investigation will be required, however, in order to confirm such associations.

In the population studied, mothers and heads of households who had received low levels of schooling were shown to be most likely to produce stunted children. It is known that the level of maternal education directly influences the health of the offspring, since mothers are responsible for providing care to the children during the critical years of intense growth and development ${ }^{(28)}$. However, the association between low level of schooling and stunted children remained even after multiple analysis and, considering the socio-economic homogeneity of the sample population, the question arises as to whether such an association was a problem of collinearity or if individuals suffering from the sequels of undernutrition present less aptitude for learning.

Following multiple linear regression analysis, it was possible to observe that mothers of short stature were also the oldest, and this suggests a secular tendency of the evolution of stature ${ }^{(29)}$. Such a finding identifies a limitation of the present study, however, since it was not possible to determine whether the stature of shorter mothers had been influenced by their early nutritional status.

The present study revealed that menarche was earlier amongst mothers of shorter stature. Since at the time of study these mothers were fatter than those of higher stature, it is possible to speculate that shorter women would also be fatter during adolescence, and this could explain menarche at an earlier age. On the basis of a review of recent literature, Kaplowitz ${ }^{(30)}$ reported that the onset of puberty in girls has occurred earlier over the past 30 years, and this is probably due to increasing rates of obesity in children over the same time period. Several studies have shown that girls presenting larger BMI values are more likely to menstruate earlier ${ }^{(30)}$, and a growing body of evidence suggests that leptin may be the critical link between body fat and early puberty. The link between the female reproductive axis and body fat may have evolved in mammals as a mechanism for ensuring that pregnancy would not occur unless adequate fat stores were available to sustain both the mother and the growing fetus.

Frisancho ${ }^{(31)}$ has suggested the application of the 5th percentile of the reference population to define short stature in adults. The cut-off point in the definition of short stature in women adopted in the present study was the 25 th percentile of the height distribution in the population studied. The height of women classified in this category was $\leq 1.52 \mathrm{~m}$, a limit that is lower than that of the 5 th percentile cut-off point of the height distribution in 20-year-old individuals $(1.589 \mathrm{~m})$ used as a reference by the Centers for Disease Control and Prevention ${ }^{(32)}$. On the other hand, the cut-off point for women in the 4 th quartile (i.e. the 75 th percentile) is equivalent to a height $>1.59 \mathrm{~m}$, a value that corresponds with the 25 th percentile in the reference standard ${ }^{(32)}$. On the basis of such comparisons, it is possible to state that the environment represented an important epidemiological determinant of short stature in the population studied. Further comparison suggests that even women included in the 4th quartile lacked the health and nutritional conditions necessary for perfect growth and development. In this case, the associations found in the present study could be weaker than indicated since women classified in the 4th quartile did not represent a gold standard for comparison. However, marked differences were found between mothers of short and normal stature with respect to frequency of obesity (despite the poor living conditions) and hypertension, all aspects that corroborated the Barker hypothesis ${ }^{(6)}$.

In conclusion, the low maternal stature of the study population, which had been submitted to chronic food insecurity, was independently associated with obesity and hypertension, and also less healthy offspring, reinforcing the hypothesis that undernutrition during early life results in permanent harm to the health of the individual with serious consequences in adulthood.

\section{Acknowledgements}

The authors wish to thank the Conselho Nacional de Desenvolvimento Científico e Tecnológico - CNPq (grant number 401925/2005-6) and the Fundação de Amparo à Pesquisa do Estado de Alagoas - FAPEAL (grant number 011/2004 PPSUS/AL) for financial support. H. S. F. coordinated the project, trained the undergraduate students before the interviews, supervised the field workand revised the final version of the manuscript. F. A. M. reviewed the literature, wrote the preliminary version of the manuscript, tabulated the results and performed the analysis of data. C. R. C. J. assisted with the statistical analysis; T. M. M. T. F. participated in the experimental design; R. C. V. supervised the fieldwork; M. L. A. contributed with a review of the relevant literature. All authors contributed to the analysis and discussion of the results, and in the construction of the final version of the manuscript.

There were no conflicts concerning the subject material of this paper and the interests of the authors concerned. 


\section{References}

1. Caballero B (2001) Symposium: obesity in developing countries: biological and ecological factors. J Nutr 131, S866-S870.

2. Peña $\mathbf{M} \&$ Bacallao $\mathbf{J}$ (2000) Obesity among the poor: an emerging problem in Latin America and the Caribbean). In Obesity and Poverty: A New Public Health Challenge, Scientific Publication 576, pp. 3-12 [M Peña and J Bacallao, editors] Washington, DC: Pan American Health Organization.

3. Instituto Brasileiro de Geografia e Estatística (IBGE) (2008) Excesso de peso atinge 38,8 milhões de brasileiros adultos (Excess weight reaches 38.8 million Brazilian adults) http://www.ibge.gov.br/ home/presidencia/noticias/noticia_visualiza.php?id_noticia $=278 \&$ id_pagina $=1$

4. Prentice AM (2006) The emerging epidemic of obesity in developing countries. Int J Epidemiol 35, 93-99.

5. Florêncio TMMT, Ferreira HS, Luciano SM, Cavalcante JC \& Sawaya AL (2003) Food consumed does not account for the higher prevalence of obesity among short-statured adults in a very-low-income population in the northeast of Brazil (Maceió Alagoas). Eur J Clin Nutr 57, 1437-1446.

6. Barker DJP (2007) Obesity and early life. Obesity Rev 8, 45-49.

7. Kuzawa CW (2004) Modeling fetal adaptation to nutrient restriction: testing the fetal origins hypothesis with a supplydemand model. J Nutr 134, 194-200.

8. Barker DJP \& Clark PM (1997) Fetal undernutrition and disease in later life. Rev Reprod 2, 105-112.

9. Sorensen HT, Sabroe S, Rothman KJ, Gillman M, Steffensem FH, Fisher P \& Serensen TIA (1999) Birth weight and length as predictors for adult height. Am J Epidemiol 149, $726-729$.

10. Florêncio TT, Ferreira HS, Cavalcante JC, Stux GR \& Sawaya AL (2007) Short stature, abdominal obesity, insulin resistance and alterations in lipid profile in very low-income women living in Maceió, North-Eastern Brazil. Eur J Cardiovasc Prev Rehabil 14, 346-348.

11. Ferreira HS, Florêncio TMMT, Fragoso MAC, Melo FP \& Silva TG (2005) Hipertensão, obesidade abdominal e baixa estatura: aspectos da transição nutricional em uma população favelada (Hypertension, abdominal obesity and small stature: aspects of the nutritional transition in a favela population). Rev Nutr 18, 209-218.

12. Sichieri R, Taddei JA \& Everhart JE (2000) Influence of parental height and sociodemographic factors on adolescent height in Brazil. J Adolesc Health 26, 414-419.

13. Saenger P, Czernichow P, Hughes I \& Reiter EO (2007) Small for gestational age: short stature and beyond. Endocr Rev 8, 219-251.

14. Monteiro CA (2000) The epidemiologic transition in Brazil. In Obesity and Poverty: a New Public Health Challenge, Scientific Publication 576, pp. 67-76 [M Peña and J Bacallao, editors]. Washington, DC: Pan American Health Organization.

15. Urani A (2005) Um Diagnóstico Socioeconômico do Estado de Alagoas a Partir de Uma Leitura dos Dados da Pesquisa Nacional por Amostra de Domicílios do IBGE (1992-2004) (A Socio-economic Diagnosis of the State of Alagoas from a Reading of the Data of the National Research for Sample of Domiciles of the IBGE (1992-2004)). Rio de Janeiro: Instituto de Estudos do Trabalho e Sociedade.

16. Batista Filho M (2006) Chamada nutricional: um estudo sobre a situação nutricional das crianças do semi-árido brasileiro.
Introdução (Nutritional call: a study on the nutritional situation of the children of semi-arid Brazil. Introduction) Cadernos de Estudos Desenvolvimento Social em Debate 4, $9-16$

17. Ferreira HS, Assunção ML, Florêncio TMMT \& Lima MAA (2006) Estado nutricional de pré-escolares da região semiárida do estado de Alagoas (Nutritional state of preschoolers of the semi-arid region of the state of Alagoas) Cadernos Estudos Desenvolvimento Social em Debate 4, 37-42

18. Martins IS \& Marinho SP (2003) O potencial diagnóstico dos indicadores de obesidade centralizada (Diagnostic potential of the indicators of central obesity). Rev Saude Publ 37, 760-767.

19. Gomes MAM, Nobre F, Amodeo C, et al. (2004) IV Diretrizes Brasileiras de Hipertensão Arterial. Arq Bras Cardiol 82, Suppl. 4, 7-14.

20. World Health Organization (1995) Physical Status: The Use and Interpretation of Anthropometry. WHO Technical Report Series no. 854. Geneva: WHO.

21. World Health Organization (1998) Obesity: Preventing and Managing the Global Epidemic. Report of a WHO Consultation on Obesity. Geneva: WHO.

22. Associação Brasileira de Empresas de Pesquisa (2006) Critério de Classificação Econômica Brasil (Criteria for economic classification in Brazil) http://www.abep.org

23. Gujarati DN (2000) Econometria Básica (Basic Econometry), 3rd ed. São Paulo: Makron Books do Brasil.

24. Watkins K (2005) Relatório do Desenvolvimento Humano 2005 (Report of Human Development 2005). United Nations Development Program. New York: PNUD.

25. Carvalho MS, Cruz OG \& Nobre FF (1997) Perfil de risco: método multivariado de classificação sócio-econômica de microáreas urbanas - os setores censitários da região metropolitana do Rio de Janeiro (Profile of risk: multivariate method of socio-economic classification of urban micro-areas - the census sectors of the metropolitan region of Rio de Janeiro). Cad Saude Publ 13, $635-645$.

26. Leeson CP, Kattenhorn M, Deanfield JE \& Lucas A (2001) Duration of breast feeding and arterial distensibility in early adult life: population based study. BMJ 322, 643-647.

27. Emanuel I, Kimpo C \& Moceri V (2004) The association of maternal growth and socio-economic measures with infant birthweight in four ethnic groups. Int $J$ Epidemiol 33, $1236-1242$.

28. Martins IS, Marinho SP, Oliveira DC \& Araújo EAC (2007) Pobreza, desnutrição e obesidade: inter-relação de estados nutricionais de indivíduos de uma mesma família (Poverty, malnutrition and obesity: interrelationships among the nutritional status of members of the same family). Cienc Saude Col 12, 1553-1565.

29. Kac G (1999) Tendência secular em estatura: uma revisão da literatura (Secular trends in stature: a revision of the literature). Cad Saúde Pub 15, 451-461.

30. Kaplowitz PB (2008) Link between body fat and the timing of puberty. Pediatrics 121, Suppl. 3, S208-S217.

31. Frisancho AR (1990) Anthropometric Standards for the Assessment of Growth and Nutritional Status. Ann Arbor, MI: University of Michigan Press.

32. National Center for Health Statistics (2008) National Health and Nutrition Examination Survey. 2000 CDC Growth Charts. http://www.cdc.gov/GROWTHCHARTS/ 